\title{
Comunicação
}

[Communication]

\section{Mastite subclínica por Staphylococcus coagulase negativa em ovinos de corte}

[Subclinical mastitis caused by Staphylococcus coagulase negative in meet-producing sheep]

\author{
T.S. Tejada, D.T. Silva, P.A. Dias, R.C.S. Conceição; H. Müller Neto; C.D. Timm
}

Faculdade de Veterinária - Universidade Federal de Pelotas - Pelotas, RS

\begin{abstract}
A presença de micro-organismos patogênicos no leite pode constituir um problema para o sistema de produção de ovinos de carne devido à diminuição da produção de leite e consequente comprometimento do desenvolvimento do cordeiro (Tonetto et al., 2004). A eliminação desses micro-organismos é dificultada quando eles apresentam resistência a antimicrobianos. $\mathrm{O}$ objetivo do trabalho foi verificar a ocorrência de agentes causadores de mastite isolados de leite de ovelhas de corte, bem como testar a resistência dos isolados frente a antimicrobianos.
\end{abstract}

Foram estudadas 21 ovelhas da raça Corriedale, de primeira cria, em lactação, mantidas em semiconfinamento. A sanidade das glândulas mamárias foi avaliada semanalmente, por meio da realização de California Mastitis Test - CMT (Schalm e Noorlander, 1957) e de exame clínico, a partir da semana seguinte ao parto, durante seis semanas. Isolamento em ágar sangue de ovino 5\% (Merck, Darmstadt, Germany) e identificação dos agentes infecciosos, segundo Koneman et al. (2001), foram realizados a partir dos leites positivos no CMT. Staphylococcus coagulase negativos foram identificados com uso do kit GP Test Kit Vitek $2^{\circledR}$ (BioMérieux).

A sensibilidade dos isolados a antimicrobianos foi realizada por meio da técnica de difusão, segundo NCCLS (National..., 2002), utilizandose discos com os antibióticos ampicilina $(10 \mu \mathrm{g}), \quad$ amoxicilina $(10 \mu \mathrm{g}), \quad$ bacitracina (10UI), cefalexina $(30 \mu \mathrm{g}), \quad$ gentamicina $(10 \mu \mathrm{g}), \quad$ neomicina $(30 \mu \mathrm{g}), \quad$ norfloxacina $(10 \mu \mathrm{g})$, penicilina $(10 \mathrm{UI})$ e tetraciclina $(30 \mu \mathrm{g})$.
Não foram observadas mastites clínicas. Oitenta e oito amostras de leite apresentaram resultado positivo no CMT. As prevalências de mastite variaram de $23,8 \%$ a $80,9 \%$ (Fig. 1), sendo o agente etiológico identificado em 26 (29,5\%) amostras de leite. Al-Majali e Jawabreh (2003) sugerem que resultados positivos no CMT sem isolamento de bactérias do leite podem ser devido a um aumento de células somáticas no leite após o término da infecção ou a mastites não infecciosas.

Os agentes etiológicos identificados foram Staphyloccus lentus (7 isolados), Staphyloccus sciuri (5), Staphyloccus vitulinus (2), Staphyloccus haemolyticus (1), Staphyloccus epidermidis (1), Aerococcus viridans (1) e Entrococcus faecium (1). Oito isolados não foram identificados pelo método utilizado.

Staphylococcus coagulase negativos foram os agentes etiológicos mais frequentes (94\%). Estes micro-organismos têm sido comumente implicados em mastites subclínicas em ovelhas leiteiras (Berthelot et al., 2006; Bolsanello et al., 2008). O presente estudo demonstrou que Staphylococcus coagulase negativos são importantes agentes de mastite também em ovinos de corte. Segundo Fragkou et al. (2007), a microbiota de Staphylococcus presente no interior do ducto do teto pode agir competitivamente contra a invasão e a colonização por outros micro-organismos patogênicos, sendo um mecanismo de defesa da glândula. Contudo, se houver uma falha no mecanismo de defesa, a própria microbiota pode invadir o parênquima mamário e causar mastite.

Recebido em 28 de março de 2012

Aceito em 1 de agosto de 2012

E-mail: inspleit@ufpel.tche.br 


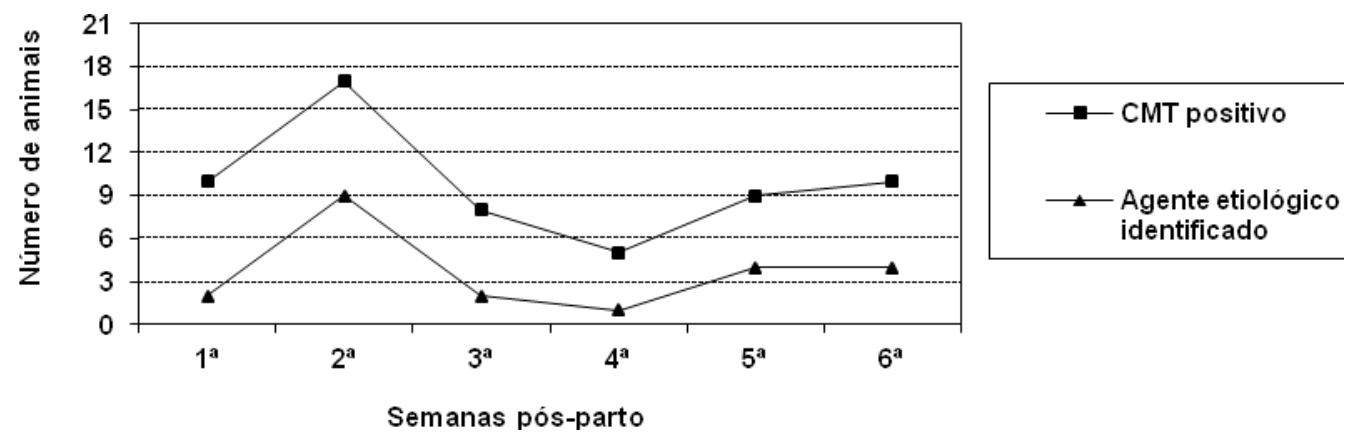

Figura 1. Animais com leite positivo no California Mastitis Test (CMT) em pelo menos uma glândula mamária e isolamentos de agentes etiológicos do leite.

S. lentus foi o agente mais isolado do leite das glândulas mamárias com mastite. Este microrganismo é um comensal da microbiota dos ovinos e pode causar mastite devido ao seu caráter oportunista (Zhang et al., 2009). S. lentus e S. sciuri (o segundo agente mais freqüente) têm sido isolados em outros estudos não só do leite de ovelhas leiteiras, mas também dos animais, dos equipamentos e do ambiente de ordenha (Berthelot et al., 2006; Zhang et al., 2009).

Somente dois animais apresentaram infecção persistente, repetindo o resultado positivo no CMT durante duas semanas consecutivas. Outros seis animais apresentaram resultados positivos em períodos diferentes. Três animais apresentaram mastites em ambas as glândulas mamárias na mesma semana. É possível que os cordeiros tenham agido como transmissores do agente infeccioso entre as glândulas mamárias. Segundo Gougoulis et al. (2008), a sucção dos cordeiros aumenta o risco de infecção do canal do teto de ovelhas, pois podem transferir bactérias da pele do teto ou da própria boca para o interior do ducto.

Os antimicrobianos gentamicina, norfloxacina, cefalexina e amoxicilina foram os que apresentaram maior efetividade no controle na multiplicação dos Staphylococcus coagulase negativos in vitro (Tab. 1). Foi observada grande resistência a alguns antibióticos, principalmente ampicilina e penicilina, com $73,1 \%$ e $69,2 \%$ das cepas resistentes, respectivamente.

Tabela 1. Sensibilidade dos micro-organismos isolados frente a diferentes antibióticos

\begin{tabular}{lccc}
\hline Antimicrobiano & Cepas sensíveis & Cepas intermediárias & Cepas resistentes \\
\hline Ampicilina & 6 & 1 & 19 \\
Amoxicilina & 23 & 0 & 3 \\
Bacitracina & 15 & 0 & 11 \\
Cefalexina & 23 & 3 & 0 \\
Gentamicina & 25 & 1 & 0 \\
Neomicina & 5 & 16 & 5 \\
Norfloxacina & 24 & 2 & 0 \\
Penicilina & 8 & 0 & 18 \\
Tetraciclina & 18 & 4 & 4 \\
\hline
\end{tabular}

O processo inflamatório na glândula mamária, além da diminuição na produção de leite, também altera sua qualidade nutricional, diminuindo a concentração de gorduras e proteínas (Moroni et al., 2007). Estas alterações têm influência direta no sistema de produção de ovinos, pois o desenvolvimento dos cordeiros está intimamente relacionado ao consumo de leite, principalmente durante as primeiras semanas de vida (Tonetto et al., 2004). A ocorrência de agentes etiológicos de mastite resistentes a antibióticos serve de alerta quanto ao uso indiscriminado de antibióticos nos sistemas de produção ovina.

Palavras-chave: coagulase negativa, mastite, ovinos, Staphylococcus 


\begin{abstract}
Microorganisms that cause mastitis were isolated in a herd of sheep and their sensitivity to antimicrobials was tested. Twenty-one sheep had their mammary glands monitored during lactation. Eighty-eight milk sample from CMT-positive sheep were analyzed in order to isolate the etiologic agent of mastitis. Coagulase negative Staphylococcus were isolated from 29.5\% of samples. Ampicillin and penicillin were the antimicrobials with higher number of resistant strains. The importance of coagulase negative staphylococci has been demonstrated, especially S. lentus and S. sciuri as a cause of ovine mastitis.
\end{abstract}

Keywords: coagulase negative, mastitis, sheep, Staphylococcus

\section{REFERÊNCIAS}

AL-MAJALI, A.M.; JAWABREH, S. Period prevalence and etiology of subclinical mastitis in Awassi sheep in southern Jordan. Small Rum. Res., v.47, p.243-248, 2003.

BERTHELOT, X.; LAGRIFFOUL， G.; CONCORDET, D. et al. Physiological and pathological thresholds of somatic cell counts in ewe milk. Small Rum. Res., v.62, p.27-30, 2006.

BOLSANELLO, R.X.; HARTMAN, M.; DOMINGUES, P.F. et al. Etiologia da mastite em ovelhas Bergamácia submetidas à ordenha mecânica, criadas em propriedade de Botucatu, SP. Vet. Zootec., v.16, p.221-227, 2008.

FRAGKOU, I.A.; MAVROGIANNI, V.S.; CRIPPS, P.J. et al. The bacterial flora in the teat duct of ewes can protect against and can cause mastitis. Vet. Res., v.38, p.525-545, 2007.

GOUGOULIS, D.A.; KYRIAZAKIS, L.; TZORA, A. et al. Effects of lamb sucking on the bacterial flora of teat duct and mammary gland of ewes. Reprod. Dom. Anim., v.43, p.22-26, 2008.

KONEMAN, E.W.; ALLEN, S.D.; JANDA, W.M. et al. Diagnóstico Microbiológico: Texto e Atlas Colorido. 5.ed. Rio de Janeiro: MEDSI, 2001. p.1465.
MORONI, P.; PISONI, G.; VARISCO, G. et al. Effect of intramammary infection in Bergamasca meat sheep on milk parameters and lamb growth. J. Dairy Res., v.74, p.340-344, 2007.

NATIONAL committee for clinical laboratory standards - NCCLS. Performance standards for antimicrobial disk and dilution susceptibility test for bacteria isolated from animals. 2.ed. USA: NCCLS, 2002. 81p.

SCHALM, O.W.; NOORLANDER, D.D. Experiments and observations leading to development of the California Mastitis Test. $J$. Am. Vet. Med. Associat., v.130, p.199-204, 1957.

TONETTO, C.J.; PIRES, C.C.; MÜLER, L. et al. Ganho de peso e características da carcaça de cordeiros terminados em pastagem natural suplementada, pastagem cultivada de azevém (Lolium multiflorum Lam.) e confinamento. Rev. Bras. Zootec., v.33, p.225-233, 2004.

ZHANG, Y.; AGIDI, S.; LEJEUNE, J.T. Diversity of staphylococcal cassette chromosome in coagulase-negative staphylococci from animal sources. J. Appl. Microbiol., v.107, p.1375-1383, 2009. 